\title{
Introduction: the kaleidoscopic world of REDD+
}

\section{Christina Voigt}

REDD+ is a phenomenon. Arguably, no other aspect of the climate regime established under the UNFCCC is characterized by the intersection of as many and as varied international and national legal instruments.

Neither has any other climate aspect attracted the attention of the legal community working with questions of regime interaction and interplay, consistency and/or fragmentation of international law and polycentricity to the extent REDD+ has. The purpose of this book is to capitalize on this work and to inquire how and to what extent REDD+ is embedded in the international legal framework.

The research handbook takes a qualitative approach and looks at REDD+ from the perspective of international law. It attempts to analyze the challenges, innovations, shortcomings, and successes that are already part of the international legal framework for REDD+ or can be expected to arise.

Complexity is inherent in the very idea of REDD+. Conceived as an incentive instrument under the UNFCCC for developing countries to adopt and scale up climate mitigation actions in the forest sector, it mirrors in its design the pluralistic interests - and trade-offs - that characterize that sector. Perhaps more than any other sector, the forest sector amplifies multiple objectives, ranging from resource exploitation, land management, agriculture, food and fuel production, ecosystem services, biodiversity protection to providing people with livelihoods, amenities, and sanctuaries.

Already the acronym "REDD+," which aims at capturing under one and the same heading such widely differing activities as reducing emissions from deforestation and from forest degradation (the "REDD") as well as conservation and enhancement of forest carbon stocks and the sustainable management of forests (the "+"), gives an indication of the concept's multi-faceted character. ${ }^{1}$ Underlying the (surprising) diversity of REDD+ activities is the understanding that slowing, halting, and eventually revers-

1 See Chapter 1, "History and future of REDD+ in the UNFCCC: Issues and challenges" by Antonio G.M. La Viña, Alaya de Leon, and Reginald Rex Barrer. 
ing forest cover and carbon loss will have to comprise of a range of policy approaches, national circumstances taken into account. Yet each activity comes with its own set of challenges and opportunities, some more readily explored than others.

REDD+ aims at incentivizing mitigation action in developing countries and at capturing and channeling developed countries' financial resources to do so. As a "bridging tool" between those countries that provide support and those that receive it, REDD+ is built upon clear methodologies and a robust framework for measuring, reporting, and verification as well as a high degree of transparency which is singular in the regulatory scheme under the UNFCCC. Importantly, the UNFCCC REDD+ framework has achieved a careful balance between environmental integrity and stringency of requirements to obtain financial support, while allowing for flexibility to accommodate the diversity of REDD+ countries and to allow for broad participation. ${ }^{2}$

However, the interface between the internationally agreed guidelines for REDD+ and national policy- and law-making is broad and diffuse. UNFCCC guidance on REDD+, if implemented, significantly delimits the sovereign space of those developing countries wishing to engage in REDD+, in particular if ex post payments for verifiably achieved emission reductions are being sought. Such "vertical interface" between the national and the international legal framework raises interesting questions pertaining to the role and force of international law vis-à-vis sovereignty claims over natural resources which both are of importance to the territorial state and also of collective importance to the global community. Which normative parameters for countries' exercise of sovereign discretion can legitimately be designed by international rules, and which levers for implementation, e.g. incentives or conditionalities, are politically feasible?

Another important aspect of REDD+ is the "horizontal interface" between REDD+ as a climate mitigation and finance instrument under the UNFCCC and other areas of international law. REDD+ is of indisputable relevance to various international legal regimes and vice versa. Multiple international legal instruments (already or potentially) interact with REDD+, both in terms of designing and implementing REDD+ policies at the national level, and carving out the legitimate normative space for REDD+ in the wider frame of international law.

2 See Chapter 2, "The Warsaw Framework for REDD+: Implications for national implementation and results-based finance" by Christina Voigt and Felipe Ferreira. 
As mentioned above, the genesis of REDD+ is a case example par excellence of regime interaction and interplay. REDD+ begs (and, to a certain extent, answers) questions as to the consequences of such interaction: is it synergetic or conflicting, does it develop ad hoc and chaotic or with a certain degree of consistency and foresight, does it lead to stronger integration or rather intensifies fragmentation ${ }^{3}$ Are we witnessing an emerging puzzle of international instruments where the pieces fall into their (normative) place, or is what we see a constant re-alignment of the law to the ever-changing political priorities, or, interestingly, both? Like a kaleidoscope, where external "shocks" do not lead to disruption but renewal, the continuous re-configuration of the colorful mosaic (of norms) in response to changing circumstances is proof of the REDD+ regime's strength, durability and resilience.

Regime interaction does and will occur for many reasons and in many ways. In the absence of a neutral ground to manage it, it should be viewed as a necessary and welcome way to adapt REDD+ to the realities of a pluricentric international legal system. ${ }^{4}$

With regard to REDD+, the interaction mirrors the diverse but overlapping axes of interests crossing the forest sector, most prominent among them (1) economic and developmental interests in the forest resource base with regard to timber, agricultural land, or extraction of sub-soil minerals and hydrocarbons, (2) interests that recognize forests as home and host for biological diversity and a multitude of ecological services, (3) interests in the human dimension of forests in terms of livelihoods, rights of forest-dependent people as well as participatory arrangements in decision-making, and (4) interests in good governance - especially in addressing corruption and other fiduciary risks, ${ }^{5}$ legitimacy and multilevel governance, ${ }^{6}$ adaptive management, ${ }^{7}$ and the rule of law. ${ }^{8}$

3 See Chapter 3, "The institutional complex for REDD+: A 'benevolent jigsaw"? by Harro van Asselt and Constance L. McDermott, as well as Chapter 4, "REDD+ and interacting legal regimes" by Margaret A. Young.

4 On the notion of "regime management," see Martti Koskenniemi, "Hegemonic Regimes" in: Margaret A. Young (ed.), Regime Interaction in International Law: Facing Fragmentation (Cambridge University Press, 2012), 305.

5 See Chapter 12, "Managing fiduciary risk in REDD+" by Paul Keenlyside, John Costenbader, and Charlie Parker.

6 See Chapter 10, "REDD+ and multilevel governance beyond the climate negotiations" by Ernesto Roessing Neto and Joyeeta Gupta.

7 See Chapter 14, "Rediscovering ambition, implementation and operationalization" by Patricia Elias.

8 See Chapter 15, "Adjudicating disputes across scales: global administrative law considerations for REDD+" by Kristen Hite and Chapter 9, "REDD+, 
Accordingly, one such axis runs along addressing the drivers of deforestation and forest degradation through direct or indirect regulation. The necessary legal measures, however, may have implications for countries which have committed to trade liberalization and/or investment protection.

REDD+ may in itself be described as a form of sustainable investment in the forest sector. In this light, the role of international trade and investment rules is nuanced, ${ }^{9}$ serving as either sword or shield for the policies, economic incentives, and other laws which address drivers and enhance forest protection, with potential to encourage climate-friendly investments in sustainable landscapes. ${ }^{10}$

A second axis deals with the impacts of deforestation and enhancement of forest carbon stocks and the sustainable management of forests for the protection of biological diversity and ecosystems as well as wildlife and species protection for which a whole range of international legal instruments exist, most prominent among them the Convention on Biological Diversity. ${ }^{11}$

A third axis addresses the social dimensions of REDD+, in particular its interplay with a number of human rights instruments. REDD+ policy approaches - or the absence thereof - can have significant implications for stakeholders' substantive and procedural human rights recognized in relevant international human rights agreements. Landowners, indigenous peoples, local communities, as well as affected individuals may hold rights that could be impacted by REDD+ policies. On the other hand, the explicit recognition of indigenous peoples' rights and rights of local communities in the context of REDD+ safeguards has, arguably, led to increased visibility and gains in the recognition of those rights. ${ }^{12}$

An important feature of the UNFCCC framework for REDD+ is thus the introduction of safeguards. ${ }^{13}$ REDD + safeguards direct

tenure and indigenous property: The promise and peril of a 'human rights-based approach"” by Kirsty Gover.

9 See Chapter 8, "Addressing drivers of deforestation and forest degradation through international law" by Charlotte Streck and Michaela Schwedeler.

10 See Chapter 13, "REDD+ instruments, international investment rules and sustainable landscapes" by Marie-Claire Cordonier Segger, Markus Gehring, and Andrew Wardell.

11 See Chapter 7, "The Convention on Biological Diversity and REDD+" by Andrew Long and Chapter 11, "Seeing the forest for the trees: Getting post-Earth Summit forest protection back on track" by Peter Horne.

12 See Chapter 6, "The human rights of indigenous peoples and forest-dependent communities in the complex legal framework for REDD+" by Sébastien Jodoin.

13 Decision 1/CP.16, The Cancun Agreements: Outcome of the Work of the Ad Hoc Working Group on Long-term Cooperative Action under the 
implementation and support of REDD+ activities beyond mitigation actions, aiming at avoiding negative social and environmental impacts and at promoting additional benefits as well as rights and interests of stakeholders. ${ }^{14}$ In REDD+ parlance, safeguards need to be "addressed and respected" throughout the implementation of all REDD+ activities in an open and transparent manner. It is the concept of safeguards which explicitly recognizes the interplay of REDD+ with other areas of international law, most notably relevant international agreements with regard to the protection of human rights and conservation and sustainable use of biodiversity. Arguably, it was also the safeguard concept which triggered scholarly reflections on regime interaction in the context of REDD+ in the first place. In any case, safeguards and their implementation provide valid and valuable ground for such reflection. While developing countries currently are coming forward with information on how all safeguards have been addressed and respected throughout the implementation of REDD+ activities, ${ }^{15}$ empirical data is becoming accessible and accumulating which can help to back up - or reject - claims of de jure and/or de facto regime interplay between REDD+ and other international legal agreements in the context of national implementation.

The method applied in this book is reminiscent of a hermeneutic exercise where scholars, consultants, and practitioners were invited to analyze the UNFCCC framework for REDD+ as well as documents, agreements, and practice outside the UNFCCC with the aim of achieving a (more or less) coherent understanding of the interplay and interaction between REDD+ and the wider spectrum of international legal instruments. Such an approach necessarily leads to some overlaps and repetition. However, the message that emerges from this exegesis is clear: REDD + is a mosaic of overlapping instruments. Rather than calling for more coherence, the embeddedness of REDD+ in the international

Convention, UN Doc. FCCC/CP/2010/7/Add.1, 15 March 2011, Appendix I, paragraph 2, (a)-(g).

14 See Chapter 5, "The legal status and role of safeguards" by Annalisa Savaresi.

15 Decision 12/CP.17 states that developing country Parties should periodically provide a summary of information on how all the safeguards are being addressed and respected. The information should be provided in a way that ensures transparency, consistency, comprehensiveness, and effectiveness. The summary should contain information about which REDD+ activity or activities are covered and include information on national circumstances relevant to addressing and respecting the safeguards, a description of each safeguard in accordance with national circumstances, a description of existing systems and processes relevant to addressing and respecting safeguards, as well as information on how each safeguard has been addressed and respected. 
legal framework and the diversity that lies in the interplay of different legal regimes should be recognized as adding strength, resilience, and legitimacy to REDD+.

REDD+ is an experiment of scale. Diverse levels and sites of governance allow for the experimentation, testing, and diffusion of best practices and, eventually, standards. REDD+ is polycentric, dynamic, adaptive, and flexible. This is the reality which needs to be acknowledged by policy-makers as well as scholars. The fluid, kaleidoscopic diversity of legal instruments, regime interplay, and the interaction of governance arrangements offer perhaps the best "fit" between the complex challenge of addressing deforestation and the need for an adequate and flexible legal and institutional framework governing REDD+. ${ }^{16}$

With the finalization of the formal REDD+ negotiations under the UNFCCC in 2015 and the integration of the existing framework in the Paris Agreement, REDD+ is elevated to a new phase where robust methodologies and assurances of adequate and predictable support should lead to upscaled implementation. The main goal of REDD+ is to enhance action and support to slow, halt, and reverse forest cover and carbon loss in developing countries, as part of the global effort against climate change. Interaction with various international legal instruments helps to ensure that this goal is achieved while respecting also other concerns and interests of the global community.

The new Paris climate agreement encourages Parties to take action to implement and support the existing framework for REDD+ under the UNFCCC. ${ }^{17}$ Parties may therefore choose to build upon the international guidance and decisions already agreed for REDD+ for their nationally determined mitigation contributions with regard to terrestrial emissions and removals. However, the ambition to address all main emission sources and sinks will mean that REDD+ methodologies only cover a fragment of land-based emissions. The development of a common framework for all parties for all sectors, including the land sector, will take time and its outcome remains uncertain. One thing, however, is certain. The complexity of issues and interests to be taken into account will only increase when further objectives such as food and energy security, agriculture, land management, and sustainable finance and investment in land use are added to the picture. All of these diverse interests neither will, can, nor perhaps

16 On the notion of "institutional fit", see Oran R. Young, Institutional Dimensions of Environmental Change: Fit, Interplay, and Scale (Cambridge: MIT Press, 2002).

17 Decision 1/CP.21, Adoption of the Paris Agreement, Annex, Art. 5.1; FCCC/ CP/2015/L.9. 
should be addressed under the UNFCCC. Interaction and interplay with other legal instruments will therefore remain high on the legal and political agenda.

This book, it is hoped, gives impetus to further research on the possibilities and limitations, promises and consequences of such interplay. 
Christina Voigt - 9781783478316 Downloaded from PubFactory at 04/25/2023 11:16:46PM via free access 